\title{
Electrochemical Tuning of Magnetism in Ordered Mesoporous Transition Metal Ferrite Films for Micromagnetic Actuation
}

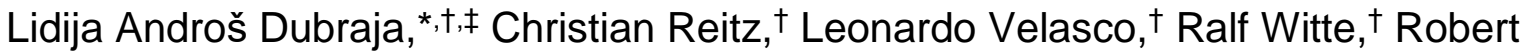 \\ Kruk, ${ }^{\dagger}$ Horst Hahn, ${ }^{\dagger}, \#$ and Torsten Brezesinski ${ }^{\star}, \dagger$
}

†Institute of Nanotechnology, Karlsruhe Institute of Technology, Hermann-vonHelmholtz-Platz 1, 76344 Eggenstein-Leopoldshafen, Germany

‡Ruđer Bošković Institute, Bijenička cesta 54, 10000 Zagreb, Croatia

\#KIT-TUD Joint Research Laboratory Nanomaterials, Technische Universität Darmstadt, 64287 Darmstadt, Germany

\section{Keywords}

Block copolymer templating, nanomagnetism, lithium-ion battery, topotactic insertion reaction, cobalt ferrite, nickel ferrite, spinel

\begin{abstract}
Controlling magnetism in situ and in a reversible manner using battery redox chemistry is a new concept in the wider field of magnetoelectrics, and electrochemical lithium tuning of electrode materials is one such approach. Here we show that the general idea of combining nanomagnetism and electrochemical energy storage concepts can be applied to ordered mesoporous spinel ferrite thin films. Via evaporation-induced self-assembly method, a series of cobalt and nickel ferrites $\left(\mathrm{CoFe}_{2} \mathrm{O}_{4}, \mathrm{Co}_{0.5} \mathrm{Ni}_{0.5} \mathrm{Fe}_{2} \mathrm{O}_{4}\right.$, and $\mathrm{NiFe}_{2} \mathrm{O}_{4}$ ) were prepared and characterized by electron microscopy, grazing-incidence small-angle X-ray scattering and wide-angle $\mathrm{X}$-ray diffraction, ${ }^{57} \mathrm{Fe}$ Mössbauer spectroscopy, and magnetometry. The dip-coated films after heating in air to temperatures beyond $600^{\circ} \mathrm{C}$ are single phase with partially inverted spinel structures and exhibit $15-20 \mathrm{~nm}$ pores of oblate spheroidal shape arranged on a cubic lattice. Magnetic measurements clearly show stable ferrimagnetic ordering at room temperature, especially for the cobalt-based materials. More importantly, when using the different transition metal ferrites as insertion electrodes in lithium-ion cells and carefully controlling the cutoff potentials, they allow for robust tuning of magnetization without compromising both the lattice and pore structure. As a potential application area, micromagnetic actuation technology is considered.
\end{abstract}




\section{Introduction}

Transition metal ferrites with a spinel structure $\left(\mathrm{MFe}_{2} \mathrm{O}_{4}\right.$ with $\mathrm{M}=\mathrm{Co}^{2+}, \mathrm{Ni}^{2+}, \mathrm{Cu}^{2+}$, $\mathrm{Zn}^{2+}$ etc.) are used in a wide variety of technological applications such as magnetic memory devices and biomedicine to name a few, among others, because of their intrinsic stability and intriguing physical properties. ${ }^{1-11}$ Cobalt ferrite, $\mathrm{CoFe}_{2} \mathrm{O}_{4}$, a robust and easily accessible room temperature ferrimagnetic material, is one of the most significant members of the magnetic ferrites class. ${ }^{11,12}$ Nickel ferrite, $\mathrm{NiFe}_{2} \mathrm{O}_{4}$, has also been intensively studied over the past several decades due to its high magnetization and low coercivity, making it promising for applications requiring the use of soft-magnetic materials. ${ }^{13,14}$

Both bulk $\mathrm{CoFe}_{2} \mathrm{O}_{4}$ and $\mathrm{NiFe}_{2} \mathrm{O}_{4}$ crystallize in the cubic space group $\mathrm{Fd} \overline{3} m$ and are known as inverse spinels. This means the divalent $\mathrm{Co}^{2+} / \mathrm{Ni}^{2+}$ ions are located on octahedral sites, while an equal number of $\mathrm{Fe}^{3+}$ ions reside on tetrahedral and octahedral sites. However, the cation distribution in nanocrystalline spinel ferrites is often somewhat different and, in many cases, they adopt a mixed spinel structure. ${ }^{15-}$ ${ }_{17}$ Consequently, the magnetic properties may vary considerably with grain size. ${ }^{18,19}$ It has been shown, for example, that enhancement in magnetization can be achieved with decreasing grain (or particle) size, but also with better defined crystallinity, material characteristics that are inherently difficult to reconcile. In general, the ferrimagnetism in these materials originates from the antiparallel alignment of spins between the (non-equivalent) tetrahedral and octahedral sublattices.

In recent years, spinel ferrites have also received widespread attention for their ability to electrochemically react with lithium at low potentials..$^{20,21}$ Several attempts have been made to develop high-capacity (conversion-type) anode materials based on transition metal ferrites for application in lithium-ion batteries (LIBs). Overall, it has been shown in several studies that the cyclability, including active material utilization, kinetics, and energy efficiency, can be significantly improved by using lowdimensional or porous nanostructures, which are capable of mitigating - to some extent - the problem of particle fracture due to volume changes (electrode breathing) during lithiation/delithiation and of reducing the average diffusion distance. ${ }^{22-28}$ Besides, in situ control of magnetism through lithium insertion reaction is currently drawing an increasing interest in the battery and magnetoelectrics community..$^{29-35}$ For some nanocrystalline spinel ferrites such as $\mathrm{CuFe}_{2} \mathrm{O}_{4}$ and $\mathrm{ZnFe}_{2} \mathrm{O}_{4}$, it has been demonstrated that large and reversible variations in magnetization can be achieved by carefully controlling the amount of inserted lithium (to prevent irreversible structural changes). ${ }^{31}$

Following the same line, we show here that the general idea of combining magnetism and LIB energy storage concepts can be extended to transition metal ferrites as thin films with an ordered mesoporous morphology. In search of potential room temperature magnetic materials that show promise for this kind of research, a series of cubic mesostructured thin films were prepared by evaporation-induced selfassembly (EISA) method, ${ }^{36-38}$ including $\mathrm{CoFe}_{2} \mathrm{O}_{4}, \mathrm{NiFe}_{2} \mathrm{O}_{4}$, and $\mathrm{Co}_{0.5} \mathrm{Ni}_{0.5} \mathrm{Fe}_{2} \mathrm{O}_{4}$. As 
evidenced by various state-of-the-art characterization techniques, the latter oxides can be fully crystallized while preserving nanoscale porosity, and in fact, they allow for the possibility of tuning the magnetism at room temperature through facile insertion/extraction of lithium into/from the spinel lattice.

In terms of potential applications, one can envision a large-scale manufacturing of such tunable magnets using printing or coating techniques. For example, so far highly expensive microelectromagnets are commonly used as magnetic traps or valves: ${ }^{39-42}$ consequently, (in microfluidics or micromechanics) they could be replaced by low-cost, solution-processed voltage-controlled micromagnets to sort, separate, guide or selectively block species based on their magnetic properties.

\section{Experimental}

\section{Materials}

$\mathrm{M}\left(\mathrm{NO}_{3}\right)_{2} \times 6 \mathrm{H}_{2} \mathrm{O}$ ( $\left.\mathrm{M}=\mathrm{Co}, \mathrm{Ni} ; 99.999 \%\right), \mathrm{Fe}\left(\mathrm{NO}_{3}\right)_{3} \times 9 \mathrm{H}_{2} \mathrm{O}(99.99 \%)$, lithium bis(trifluoromethanesulfonyl)imide (LiTFSI; 99.95\%), 1-ethyl-3-methylimidazolium bis(trifluoromethanesulfonyl)imide (EMIM-TFSI; $\geq 97.0 \%)$, absolute ethanol (EtOH; 99.9\%), 2-methoxyethanol (99.8\%), and glacial acetic acid (AcOH; 99.9985\%) were purchased from commercial sources. An amphiphilic diblock copolymer of KLE-type, $\mathrm{H}\left[\left(\mathrm{CH}_{2} \mathrm{CH}_{2}\right)_{0.67}\left(\mathrm{CH}_{2} \mathrm{CHCH}_{2} \mathrm{CH}_{3}\right)_{0.33}\right]_{89}\left(\mathrm{OCH}_{2} \mathrm{CH}_{2}\right)_{79} \mathrm{OH}$, was used as structuredirecting agent. Both $700 \mu \mathrm{m}$-thick $\mathrm{Si}(001)$ wafers from $\mathrm{Si}-\mathrm{Mat}$ and indium tin oxide $\left(\mathrm{In}_{2} \mathrm{O}_{3} / \mathrm{SnO}_{2}\right.$, ITO, 90:10 wt.\%)/Si(001) wafers were used as substrates. The ITO layer was prepared via DC magnetron sputtering in $\mathrm{Ar}$ atmosphere at room temperature. The working pressure was $0.1 \mathrm{~Pa}$ and the power supplied to the 3 inch target was set to $100 \mathrm{~W}$. The layer thickness was controlled at $25 \mathrm{~nm}$.

\section{Coassembly Thin Film Fabrication}

For the synthesis of $\mathrm{Co}_{0.5} \mathrm{Ni}_{0.5} \mathrm{Fe}_{2} \mathrm{O}_{4}$, KLE-type polymer $(50 \mathrm{mg}), \mathrm{Fe}\left(\mathrm{NO}_{3}\right)_{3} \times 9 \mathrm{H}_{2} \mathrm{O}$ (309.9 mg), $\mathrm{Co}\left(\mathrm{NO}_{3}\right)_{2} \times 6 \mathrm{H}_{2} \mathrm{O}(55.9 \mathrm{mg})$ and $\mathrm{Ni}\left(\mathrm{NO}_{3}\right)_{2} \times 6 \mathrm{H}_{2} \mathrm{O}(55.8 \mathrm{mg})$ were dissolved in a mixed solvent consisting of EtOH (1.2 mL), 2-methoxyethanol (1 mL), and $\mathrm{AcOH}(0.2 \mathrm{~mL})$. The starting solutions for $\mathrm{CoFe}_{2} \mathrm{O}_{4}$ and $\mathrm{NiFe}_{2} \mathrm{O}_{4}$ were obtained in the same way, but with only either $\mathrm{Co}\left(\mathrm{NO}_{3}\right)_{2} \times 6 \mathrm{H}_{2} \mathrm{O}(111.8 \mathrm{mg})$ or $\mathrm{Ni}\left(\mathrm{NO}_{3}\right)_{2} \times 6 \mathrm{H}_{2} \mathrm{O}$ (111.7 mg). Thin films were prepared by dip-coating $(5 \mathrm{~cm} / \mathrm{min}$ withdrawal rate) onto $\mathrm{Si}(001)$ and ITO/Si(001) substrates in a humidity-controlled chamber set to $26 \%$ relative humidity. After a drying period of $5 \mathrm{~min}$, the as-made films were transferred to an oven at $150^{\circ} \mathrm{C}$ for $1 \mathrm{~h}$ and then heated to $300^{\circ} \mathrm{C}$ at $0.5^{\circ} \mathrm{C} / \mathrm{min}$, followed by aging for $12 \mathrm{~h}$ to stabilize the nanoscale structure by driving condensation and decomposition reactions. Finally, the $\mathrm{CoFe}_{2} \mathrm{O}_{4} / \mathrm{Co}_{0.5} \mathrm{Ni}_{0.5} \mathrm{Fe}_{2} \mathrm{O}_{4}$ and $\mathrm{NiFe}_{2} \mathrm{O}_{4}$ films were heated to $650^{\circ} \mathrm{C}$ and $700{ }^{\circ} \mathrm{C}$, respectively, at $10^{\circ} \mathrm{C} / \mathrm{min}$ to make them fully porous and to crystallize the framework. 


\section{Cell Assembly}

Custom cells (see also CAD-drawing and photos of the cell and how it was mounted in the magnetometer in Figures S1 and S2, Supporting Information) with $600 \mu \mathrm{m}$ thick Li metal counter-electrode (Albemarle Germany GmbH), GF/A glass fiber film separator (GE Healthcare Life Sciences, Whatman) soaked with electrolyte solution (20 wt.\% LiTFSI in EMIM-TFSI), and polymer-templated mesostructured spinel ferrite thin film working electrode on ITO/Si(001) substrate were assembled in an Ar-filled glove box.

\section{Instrumentation}

Scanning electron microscopy (SEM) was performed on a LEO 1530 (Zeiss) operated $10 \mathrm{keV}$. Transmission electron microscopy (TEM) was performed both on a Tecnai F20-ST (FEI) operated at $200 \mathrm{keV}$ in TEM and nanoprobe mode for highresolution TEM (HRTEM) and scanning TEM (STEM), respectively, and on an aberration (image) corrected Titan 80-300 (FEI) operated at $300 \mathrm{keV}$. Grazingincidence small-angle X-ray scattering (GISAXS) and grazing-incidence wide-angle $X$-ray diffraction (GIWAXD) were performed at the German synchrotron radiation facility HASYLAB at DESY. The sample-to-detector distance was $2273 \mathrm{~mm}$ (for GISAXS) and the wavelength was $1.2399 \AA$. Conversion electron ${ }^{57} \mathrm{Fe}$ Mössbauer spectroscopy (CEMS) was performed at room temperature using a custom proportional counter. The Mössbauer drive was operated in linear acceleration mode and the data acquired were fitted using the software WinNORMOS. All isomer shifts are quoted relative to $\alpha-\mathrm{Fe}$ at room temperature. Magnetic susceptibility measurements were performed on a Quantum Design MPMS 3 superconducting quantum interference device (SQUID) in an applied DC magnetic field of $0.1 \mathrm{~T}$ at temperatures ranging from $1.8 \mathrm{~K}$ to $400 \mathrm{~K}$. Magnetization versus field curves were recorded at $5 \mathrm{~K}$ and $300 \mathrm{~K}$. The measured magnetic moments are representative of $240 \mathrm{~nm} \times 5 \mathrm{~mm} \times 5.5 \mathrm{~mm}$ films. Cyclic voltammetry was performed in different potential ranges (1.1-3.4 V vs Li) at sweep rates of $0.5 \mathrm{mV} / \mathrm{s}$ and $1 \mathrm{mV} / \mathrm{s}$ using an Autolab PGSTAT302 potentiostat.

\section{Results and Discussion}

The transition metal ferrite thin films used for in situ tuning experiments were prepared by dip-coating under defined conditions (relative humidity, temperature etc.) and subsequent calcination. Structural and compositional characterization was performed on samples heated to $650{ }^{\circ} \mathrm{C}\left(\mathrm{CoFe}_{2} \mathrm{O}_{4}\right.$ and $\left.\mathrm{Co}_{0.5} \mathrm{Nio} .5_{5} \mathrm{Fe}_{2} \mathrm{O}_{4}\right)$ and $700{ }^{\circ} \mathrm{C}$ (NiFe2 $\mathrm{O}_{4}$ ) by electron microscopy, synchrotron-based GISAXS and GIWAXD, and Mössbauer spectroscopy.

Figure 1 shows results from electron microscopy, specifically from SEM, high-angle annular dark-field (HAADF) STEM, and HRTEM. From the SEM images in panels a, $\mathrm{b}$, and $\mathrm{c}$, it can be seen that the different materials at the top surface are structurally well defined, with open pores around $17 \mathrm{~nm}$ in diameter arranged on a cubic lattice. 
This is also corroborated by low-magnification SEM measurements (Figure S3, Supporting Information), demonstrating further that the films are free of microcracks and other major defects. Besides, we note that direct comparison of the nanoscale structure for films on $\mathrm{Si}(001)$ and ITO/Si(001) wafers shows the EISA process to be independent of substrate type. The STEM images in panel $d$ indicate that, as expected, the porosity persists through the film thickness. The crystallinity of the inorganic walls is evidenced, among others, by HRTEM and corresponding fast Fourier transforms (FFT). The images in panels e and $f$ show virtually randomly oriented and rounded spinel crystallites.

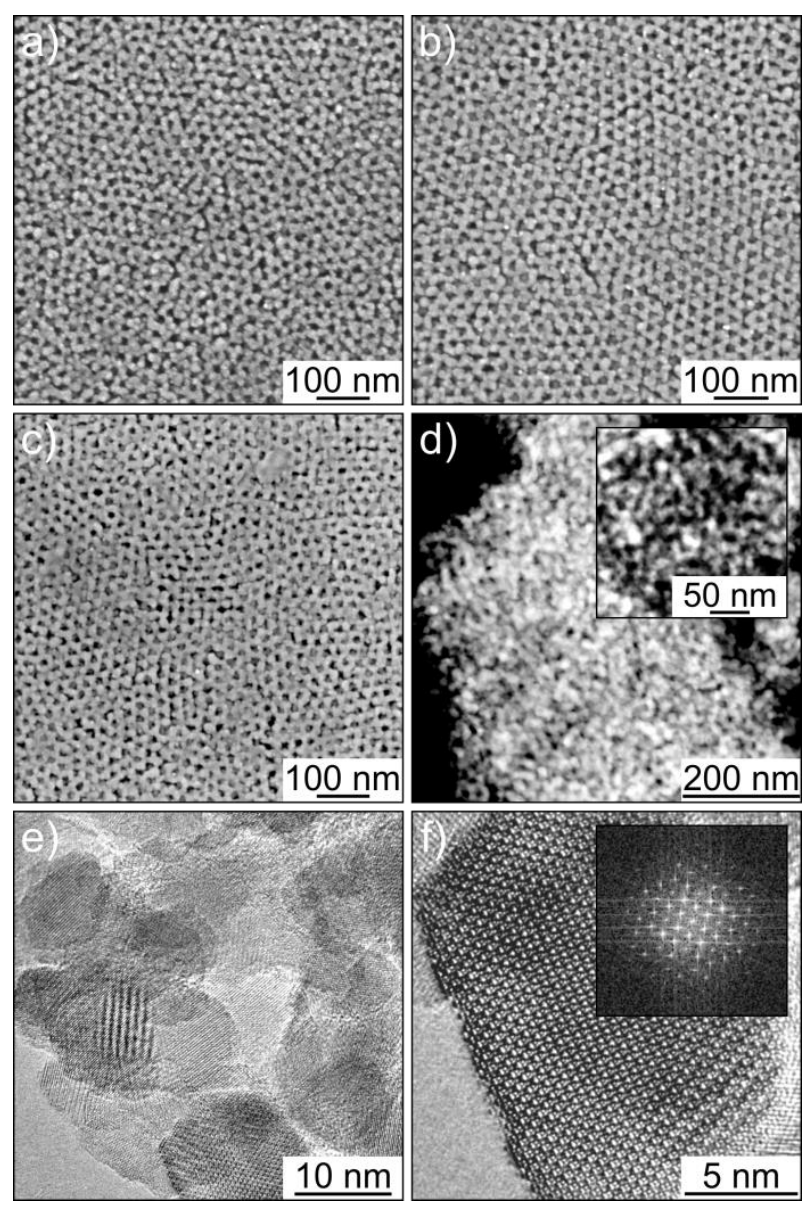

Figure 1. Electron microscopy of polymer-templated mesostructured (a) $\mathrm{CoFe}_{2} \mathrm{O}_{4}$, (b) $\mathrm{Co}_{0.5 \mathrm{Ni} .5} \mathrm{Fe}_{2} \mathrm{O}_{4}$, and (c-f) $\mathrm{NiFe}_{2} \mathrm{O}_{4}$ thin films. (a-c) Top view SEM, (d) HAADF STEM, and $(e, f)$ HRTEM images at different magnifications; the inset FFT confirms the $\mathrm{NiFe}_{2} \mathrm{O}_{4}$ structure along the [110] zone axis.

The result that the pore-solid architecture of the thin films employed here is well preserved after combustion of the KLE-type polymer and crystallization of the initially amorphous sol-gel materials is also confirmed by synchrotron-based SAXS at an angle of incidence of $0.2^{\circ}$ (referred to as GISAXS). The patterns in Figure 2 show strong scattering maxima in $\mathbf{q}_{y}$ direction, indicating that the lateral pore structure is only affected to a minor extent by the heating. The lack of scattering along $\mathbf{q}_{z}$ (out-of- 
plane direction) is due to the morphological anisotropy of the films, which is in agreement with previous findings. ${ }^{12,16,17,32,43-45}$ From the GISAXS data, we conclude that $\mathrm{NiFe}_{2} \mathrm{O}_{4}$ exhibits the highest degree of in-plane pore ordering when in the crystalline state. This material also appears to be more stable (thermally) than both $\mathrm{CoFe}_{2} \mathrm{O}_{4}$ and $\mathrm{Co}_{0.5} \mathrm{Ni}_{0.5} \mathrm{Fe}_{2} \mathrm{O}_{4}$.
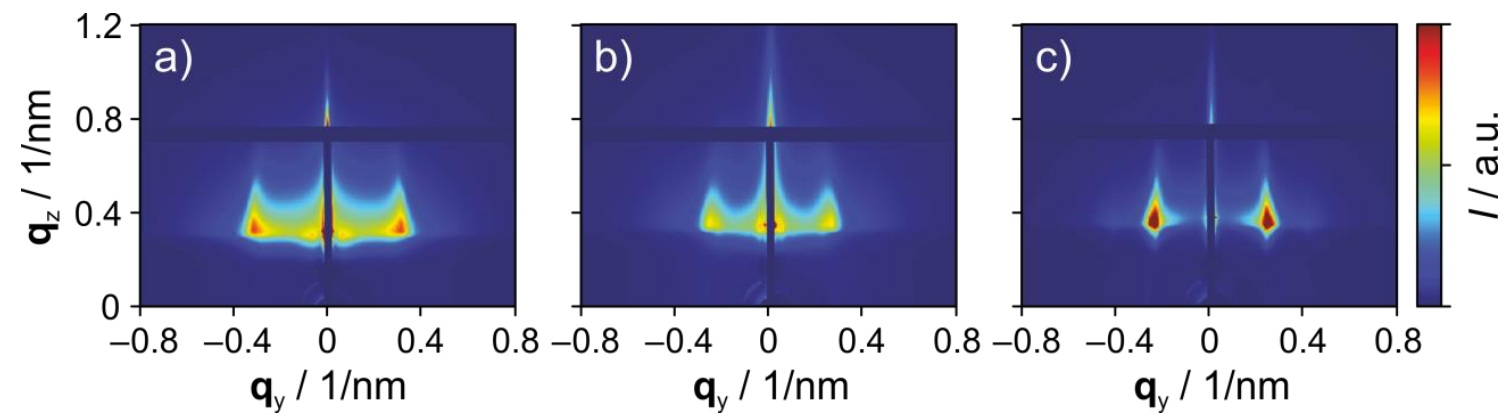

Figure 2. GISAXS patterns of polymer-templated mesostructured (a) $\mathrm{CoFe}_{2} \mathrm{O}_{4}$, (b) $\mathrm{Co}_{0.5} \mathrm{Ni}_{0.5} \mathrm{Fe}_{2} \mathrm{O}_{4}$, and (c) $\mathrm{NiFe}_{2} \mathrm{O}_{4}$ thin films.

The crystallinity and cation distribution were analyzed in more detail by synchrotronbased GIWAXD and CEMS. Figures 3a and S4 (Supporting Information) depict GIWAXD patterns of $\mathrm{CoFe}_{2} \mathrm{O}_{4}, \mathrm{Co}_{0.5} \mathrm{Ni}_{0.5} \mathrm{Fe}_{2} \mathrm{O}_{4}$, and $\mathrm{NiFe}_{2} \mathrm{O}_{4}$ thin films. Overall, the data corroborate the results obtained from HRTEM. More specifically, they show the materials to crystallize in the desired cubic space group $F d \overline{3} m$ and to be single phase spinel ferrites. The reflections match the ICSD reference codes 109044, 193421, and 28108 for $\mathrm{CoFe}_{2} \mathrm{O}_{4}, \mathrm{Co}_{0.5} \mathrm{Ni}_{0.5} \mathrm{Fe}_{2} \mathrm{O}_{4}$, and $\mathrm{NiFe}_{2} \mathrm{O}_{4}$, respectively. Typical crystallite sizes are in the range of 10-15 nm, i.e., they meet or fall below the average wall thickness observed by electron microscopy, which partially explains why porosity and pore ordering are retained.

As mentioned above, insight into the cation distribution is gained from CEMS, which gives a spectroscopic view of the local environment of the ${ }^{57} \mathrm{Fe}$ probe nuclei. Panels $b$ and $c$ of Figure 3 depict room temperature spectra obtained on $\mathrm{CoFe}_{2} \mathrm{O}_{4}$ and $\mathrm{Co}_{0.5} \mathrm{Ni}_{0.5} \mathrm{Fe}_{2} \mathrm{O}_{4}$; Mössbauer parameters from fitting of data are given in Table S1 (Supporting Information). The $\mathrm{NiFe}_{2} \mathrm{O}_{4}$ spectrum is omitted because of signs of collapse of the magnetic ordering, probably as a result of superparamagnetism in the material (see section on magnetic properties below). While it is often beneficial to perform measurements at low temperature and in the presence of an external magnetic field to be able to separate the ferrimagnetically coupled moments of $\mathrm{Fe}^{3+}$ ions on tetrahedral A and octahedral B sites, it is still possible to interpret room temperature data in a meaningful manner. The model used to fit the spectra is based on work by Sawatzky et al. ${ }^{46}$ They showed that the magnetic hyperfine fields of the two sublattices decay differently with respect to temperature, especially if the spinel structure is partially inverted. In general, one differentiates between $B$ sites that have all six neighboring tetrahedral sites occupied by $\mathrm{Fe}^{3+}$ and those having some of the tetrahedral neighbors occupied by e.g., $\mathrm{Co}^{2+}$. The magnetic hyperfine field, $B_{\mathrm{HF}}$, of 
the latter sites reduces faster with temperature because of the reduced superexchange interaction, resulting in a $B_{\mathrm{HF}}$ smaller than for the $A$ sites at room temperature. In addition, it usually shows a rather broad distribution due to the different number of $\mathrm{Co}$ or $\mathrm{Fe}$ nearest neighbors, resulting in wider absorption lines. This kind of structural disorder can be taken into account by using a Gaussian broadened sextet to represent the distribution of hyperfine parameters. In the present case, at least two subspectra from the $B$ sites (one sharp and a second broad sextet) and another sextet originating from the $A$ sites can be expected. In fact, the $\mathrm{CoFe}_{2} \mathrm{O}_{4}$ and $\mathrm{Co}_{0.5} \mathrm{Ni}_{0.5} \mathrm{Fe}_{2} \mathrm{O}_{4}$ spectra can be described by three sextets and a minor doublet component (about 7\% spectral area ratio), which is due to the presence of either trace impurities or superparamagnetic particles. The hyperfine parameters do not vary significantly with addition of $\mathrm{Ni}$, while the relative ratio of absorption lines points towards a random orientation of the magnetic domains in the film. The spectral area ratios can be taken as a measure for the $\mathrm{Fe}^{3+}$ site occupancy when assuming similar Lamb-Mössbauer factors for the A and B sites. In so doing, the compounds can be represented by the chemical formulas $\left(\mathrm{Co}_{0.32} \mathrm{Fe}_{0.68}\right)^{\mathrm{A}}\left(\mathrm{Co}_{0.68} \mathrm{Fe}_{1.32}\right)^{\mathrm{B}} \mathrm{O}_{4}$ and $\left.\left[(\mathrm{Co}, \mathrm{Ni})_{0.27} \mathrm{Fe}_{0.73}\right]^{\mathrm{A}}\left[(\mathrm{Co}, \mathrm{Ni})_{0.73} \mathrm{Fe}_{1.27}\right)\right]^{\mathrm{B}} \mathrm{O}_{4}$. We note that similar inversion parameters have been reported in the literature for transition metal ferrite nanoparticles. ${ }^{47}$ 

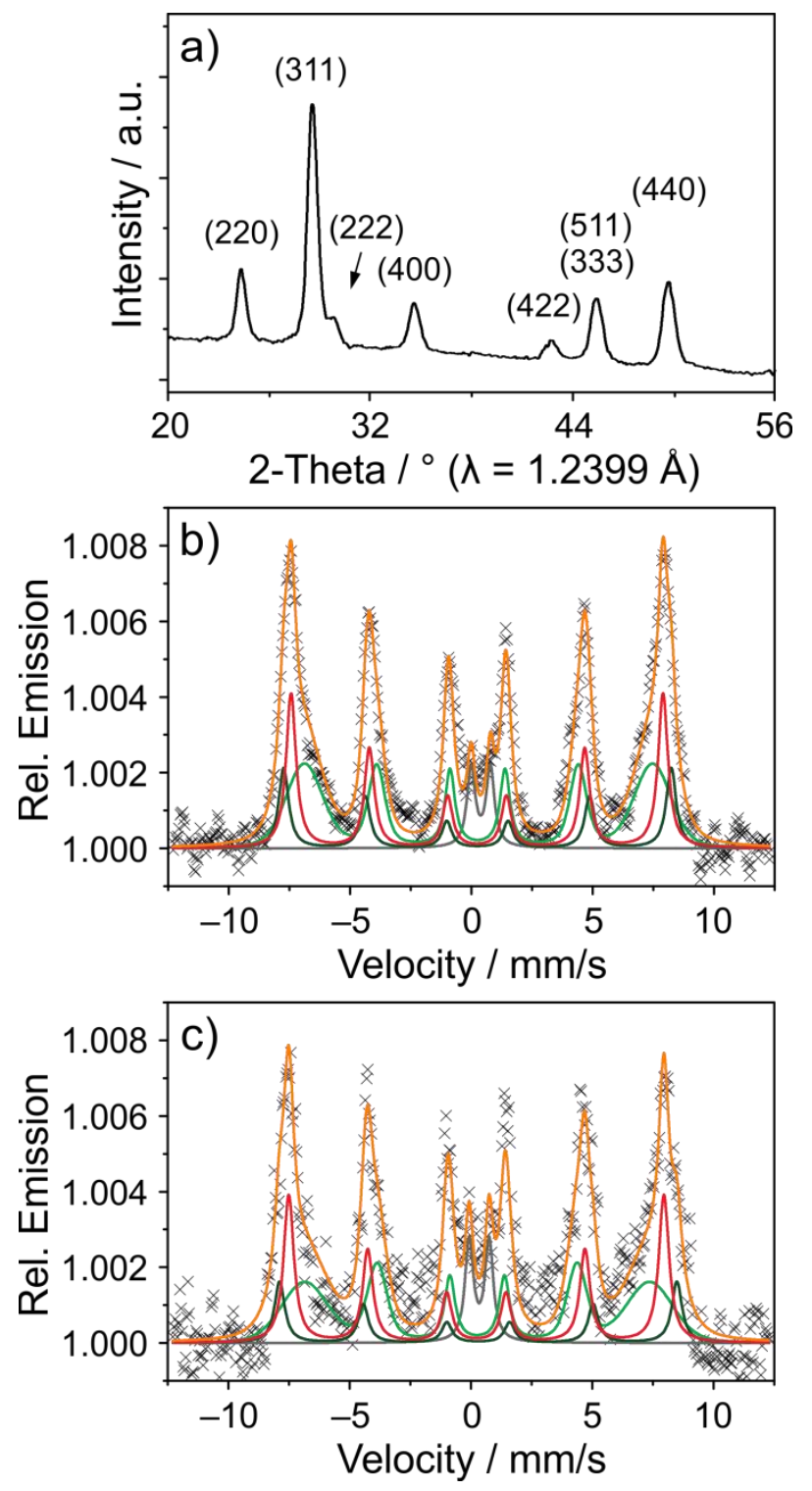

Figure 3. (a) Representative GIWAXD pattern for a polymer-templated mesostructured $\mathrm{CoFe}_{2} \mathrm{O}_{4}$ thin film. (b, c) Room temperature conversion electron Mössbauer spectra obtained on (b) $\mathrm{CoFe}_{2} \mathrm{O}_{4}$ and (c) $\mathrm{Co}_{0.5} \mathrm{Ni}_{0.5} \mathrm{Fe}_{2} \mathrm{O}_{4}$ thin films. The red line is the spectrum of $\mathrm{Fe}^{3+}$ on tetrahedral (A) sites. For octahedral $\mathrm{Fe}^{3+}$, two sextets can be distinguished as indicated by the dark green (B1) and light green (B2) lines, corresponding to sites with six or one to five $\mathrm{Fe}^{3+}$ nearest neighbors, respectively. The gray line represents the $\mathrm{Fe}^{3+}$ doublet component and the orange line is the sum of all subspectra. Although similar measuring times were used, the $\mathrm{Co}_{0.5} \mathrm{Ni}_{0.5} \mathrm{Fe}_{2} \mathrm{O}_{4}$ data have a higher signal-to-noise ratio. The seemingly new features in the spectrum in (c) are in reality only statistical variation.

The in-plane magnetic properties of the different thin films in the temperature range between $1.8 \mathrm{~K}$ and $400 \mathrm{~K}$ were investigated by means of SQUID magnetometry. Representative zero-field-cooled/field-cooled (ZFC/FC) curves at $0.1 \mathrm{~T}$ are depicted in Figure S5 (Supporting Information). Large irreversibilities are observed for all of 
the samples. For $\mathrm{NiFe}_{2} \mathrm{O}_{4}$, the $\mathrm{ZFC}$ data reach a broad maximum around $220 \mathrm{~K}$, corresponding to the blocking temperature, $T_{\mathrm{B}}$, while for $\mathrm{CoFe}_{2} \mathrm{O}_{4}$ and $\mathrm{Co}_{0.5} \mathrm{Ni}_{0.5} \mathrm{Fe}_{2} \mathrm{O}_{4}$ the magnetization increases continuously, and even at $400 \mathrm{~K}$ thermal fluctuations are suppressed, resulting in room temperature ferrimagnetic behavior. The transition temperature, $T_{\mathrm{C}}$, is beyond the range of the magnetometer used and thus could not be determined. Magnetization, $M$, vs field, $H$, curves were measured at $5 \mathrm{~K}$ and $300 \mathrm{~K}$. As is evident from the low-temperature data in Figure 4 a, both $\mathrm{CoFe}_{2} \mathrm{O}_{4}$ and $\mathrm{Co}_{0.5} \mathrm{Ni}_{0.5} \mathrm{Fe}_{2} \mathrm{O}_{4}$ can be considered hard-magnetic materials, with coercivities, $H c$, of $1.61 \mathrm{~T}$ and $0.87 \mathrm{~T}$, respectively. In contrast, the hysteresis curve reflects soft-magnetic behavior in the case of the $\mathrm{NiFe}_{2} \mathrm{O}_{4}\left(\mathrm{Hc}_{\mathrm{c}} \approx 0.045 \mathrm{~T}\right)$. The primary reason for the larger coercivity in the Co-based materials is the higher magnetocrystalline anisotropy of $\mathrm{Co}$ than $\mathrm{Ni}$. As expected, significantly lower coercivities (0.037 $\mathrm{T}$ and $0.011 \mathrm{~T}$ for $\mathrm{CoFe}_{2} \mathrm{O}_{4}$ and $\mathrm{Co}_{0.5} \mathrm{Ni}_{0.5} \mathrm{Fe}_{2} \mathrm{O}_{4}$, respectively) are found at $300 \mathrm{~K}$, with $\mathrm{NiFe}_{2} \mathrm{O}_{4}$ showing almost zero coercivity characteristic of a superparamagnetic material (Figure 4b). Collectively, the results from electron microscopy, GISAXS, GIWAXD, CEMS, and SQUID magnetometry provide profound evidence of the quality of the polymer-templated mesostructured thin films, making them good model systems.
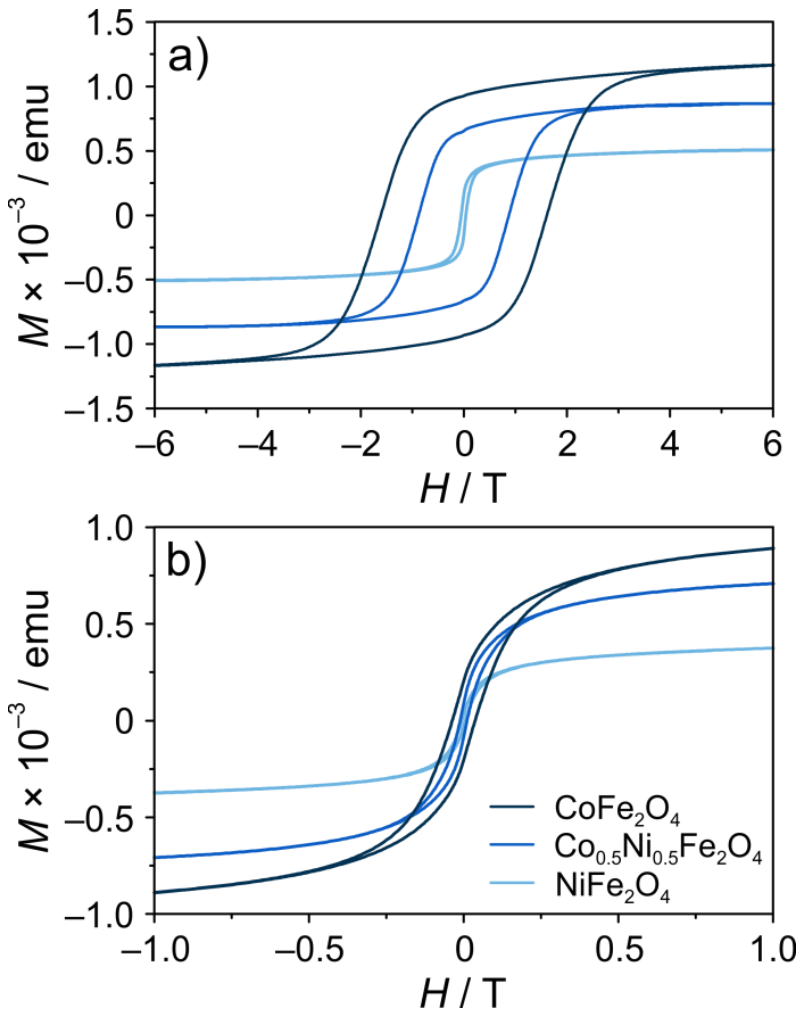

Figure 4. In-plane magnetic properties of polymer-templated mesostructured $\mathrm{CoFe}_{2} \mathrm{O}_{4}$ (black), $\mathrm{Co}_{.5} \mathrm{Ni}_{0.5} \mathrm{Fe}_{2} \mathrm{O}_{4}$ (dark blue), and $\mathrm{NiFe}_{2} \mathrm{O}_{4}$ (light blue) thin films. Magnetization versus field at (a) $5 \mathrm{~K}$ and (b) $300 \mathrm{~K}$.

As shown previously, spinel ferrites are in principle suited for magnetization modulation experiments because of the unique combination of ferrimagnetism with 
redox activity, and more importantly, because they can reversibly react with lithium in electrochemical cells (mainly reduction/oxidation of $\mathrm{Fe}$ above $\approx 1 \mathrm{~V}$ vs $\mathrm{Li}$ ). ${ }^{29,31,32,34,35}$ Note that only half of the octahedral and one eighth of the tetrahedral sites are occupied in the spinel structure, and thus there are empty lattice sites to accommodate the lithium.

The tuning experiments were performed in situ at room temperature and in an applied DC magnetic field of $0.1 \mathrm{~T}$ using custom cells with a Li metal counterelectrode (half-cell geometry). LiTFSI in EMIM-TFSI was used as electrolyte, enabling SQUID measurements under reduced pressure. ${ }^{32}$ In the following, the magnetization results are presented in terms of relative changes, $\triangle M / M$ (percent change). The total magnetic moment measured contains contributions from the whole cell. However, since the magnetic response of empty cells and those with a lithium electrode is around 100 times lower than the actual tuning signal, $\Delta M / M$ basically only reflects the behavior of the polymer-templated mesostructured thin films. The electrochemical and magnetic features with lithiation and delithiation are similar for the different electrode materials. Operating cells in a potential range between $1.1 \mathrm{~V}$ and $3.4 \mathrm{~V}$ is found to result in large irreversibilities or, in other words, low cycling efficiencies. As a result, the change in magnetic moment is not reversible. This is exemplified for $\mathrm{Co}_{0.5} \mathrm{Ni}_{0.5} \mathrm{Fe}_{2} \mathrm{O}_{4}$ in Figure $\mathrm{S} 6$ (Supporting Information). The amount of inserted lithium is greatest in the initial and second cycle, and with that also the relative change in magnetic moment $(\Delta M / M=15-20 \%)$. Yet, the magnetic moment does not reach the initial value at the end of delithiation, thus clearly indicating that deleterious side reactions occur. Unfortunately, at this point we are unable to give any reliable numbers for the specific capacity or $\mathrm{Li}$ uptake per formula unit. The reason is that the mass of films cannot be accurately determined because of the nanoscale porosity, which is very difficult to measure in practice for such thin films. Nevertheless, there is a trend towards less drift with cycling as the capacity levels off slowly. After 10 cycles, $\Delta M / M$ seems to stabilize around $5 \%$. When the potential range is narrowed from $1.1-3.4 \mathrm{~V}$ to $1.5-3.3 \mathrm{~V}$ (see also cyclic voltammogram in Figure S7a, Supporting Information), the magnetization can be controlled in a reversible manner and there is virtually no drift in $\Delta M / M$ from cycle to cycle. As shown in Figure 5a, the magnetic moment increases by about $4.5 \%$ upon lithium insertion, followed by a small decrease when the potential approaches $1.5 \mathrm{~V}$. During lithium extraction, the magnetic response is reversed; a slight increase is followed by a significant drop, reaching the initial value around the upper cutoff potential. 

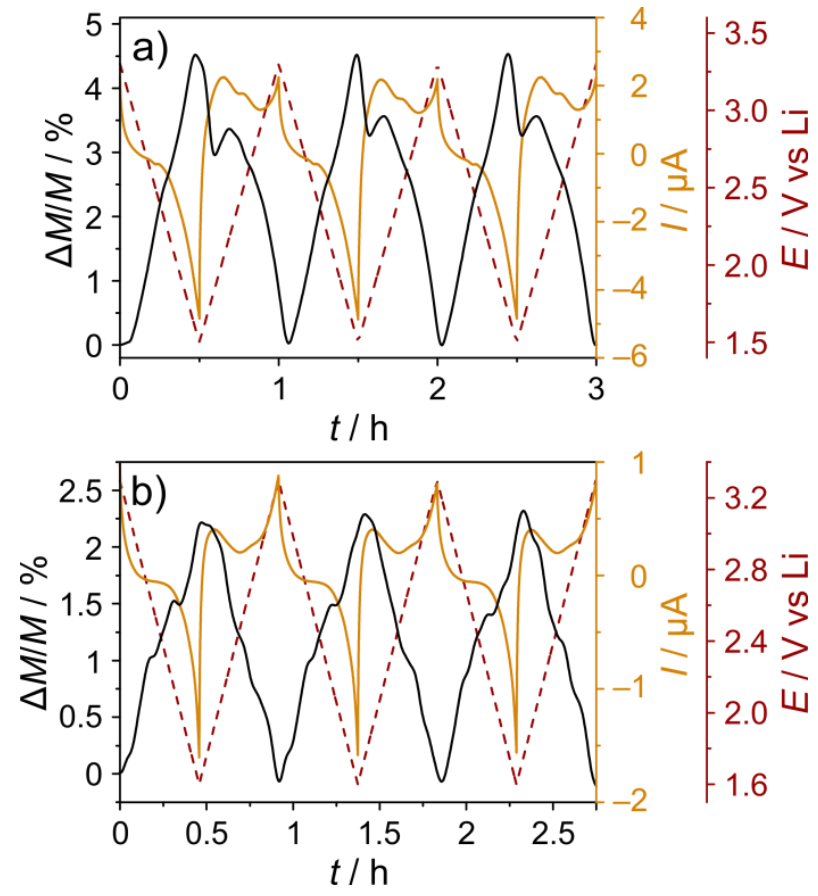

Figure 5. In situ tuning of magnetism in polymer-templated mesostructured (a) $\mathrm{Co}_{0.5} \mathrm{Ni}_{0.5} \mathrm{Fe}_{2} \mathrm{O}_{4}$ and (b) $\mathrm{CoFe}_{2} \mathrm{O}_{4}$ thin films in the potential range of $1.5-3.3 \mathrm{~V}$ and 1.65-3.3 V, respectively. Relative change in magnetic moment (solid black line) and the corresponding potential (dashed red line) and current (solid yellow line) versus the time are shown. The sweep rate was $1 \mathrm{mV} / \mathrm{s}$.

The magnetic properties of cobalt and nickel ferrites are predominantly determined by antiferromagnetic exchange interactions between the metal centers on the tetrahedral and octahedral sites (note that ferrimagnetism results from the greater proportion of atoms on the octahedral sites). When lithium is inserted into the lattice, it probably occupies the larger vacant octahedral sites (Scheme S1, Supporting Information). Since redox reactions involving $\mathrm{Co}^{2+}$ or $\mathrm{Ni}^{2+}$ are not expected to occur in the potential ranges investigated, for each lithium ion an $\mathrm{Fe}^{3+}$ is reduced to $\mathrm{Fe}^{2+}$ and the lithiated phase is created. In previous studies on spinel-type oxide materials, it was shown that tetrahedral $\mathrm{Fe}^{3+}$ ions are reduced at relatively high potentials $(\leq 1.7$ V) already. ${ }^{29,34}$ Because of the different electron configuration of $\mathrm{Fe}^{2+}$ than $\mathrm{Fe}^{3+}$, the magnetic moment of the tetrahedral sublattice decreases, leading to an increase in total magnetization (Scheme S2, Supporting Information). In addition, for $\mathrm{y}-\mathrm{Fe}_{2} \mathrm{O}_{3}$, it was experimentally confirmed that the number of Fe ions on octahedral sites increases during reduction. ${ }^{29}$ The authors explained this by the fact that the larger $\mathrm{Fe}^{2+}$ ions jump to vacant octahedral sites in the lattice (i.e., the B sublattice increases at the expense of the A sublattice). ${ }^{48,49}$ At present, however, we have no evidence for that behavior. Nevertheless, it should be noted that reduction of tetrahedral $\mathrm{Fe}^{3+}$ ions leads to positive values of $\Delta M / M$, regardless of whether the $\mathrm{Fe}^{2+}$ ions remain on tetrahedral sites or not, due to the above reasons. 
At sufficiently low potentials, octahedral $\mathrm{Fe}^{3+}$ ions are also reduced, leading to a decrease in magnetic moment (see Figures 5a and S6, Supporting Information). Since the potential range is adjusted here such that damage to the material is kept at a minimum, only a small fraction of octahedral $\mathrm{Fe}^{3+}$ ions are reduced during the course of lithium insertion. For $\mathrm{CoFe}_{2} \mathrm{O}_{4}$, where the (reversible) tuning process apparently requires an even narrower potential range (1.65-3.3 V; see also cyclic voltammogram in Figure S7b, Supporting Information), the decrease in magnetic moment with lithiation is not observed (Figure 5b).

Figure 6 depicts the magnetic response of $\mathrm{NiFe}_{2} \mathrm{O}_{4}$ during 15 cycles in the potential range between $1.4 \mathrm{~V}$ and $3.3 \mathrm{~V}$ together with the corresponding cyclic voltammograms. As is seen, the cells can be cycled stably with very little capacity loss, and this enables reversible control of magnetization, with $\triangle M / M \approx 3.5 \%$.
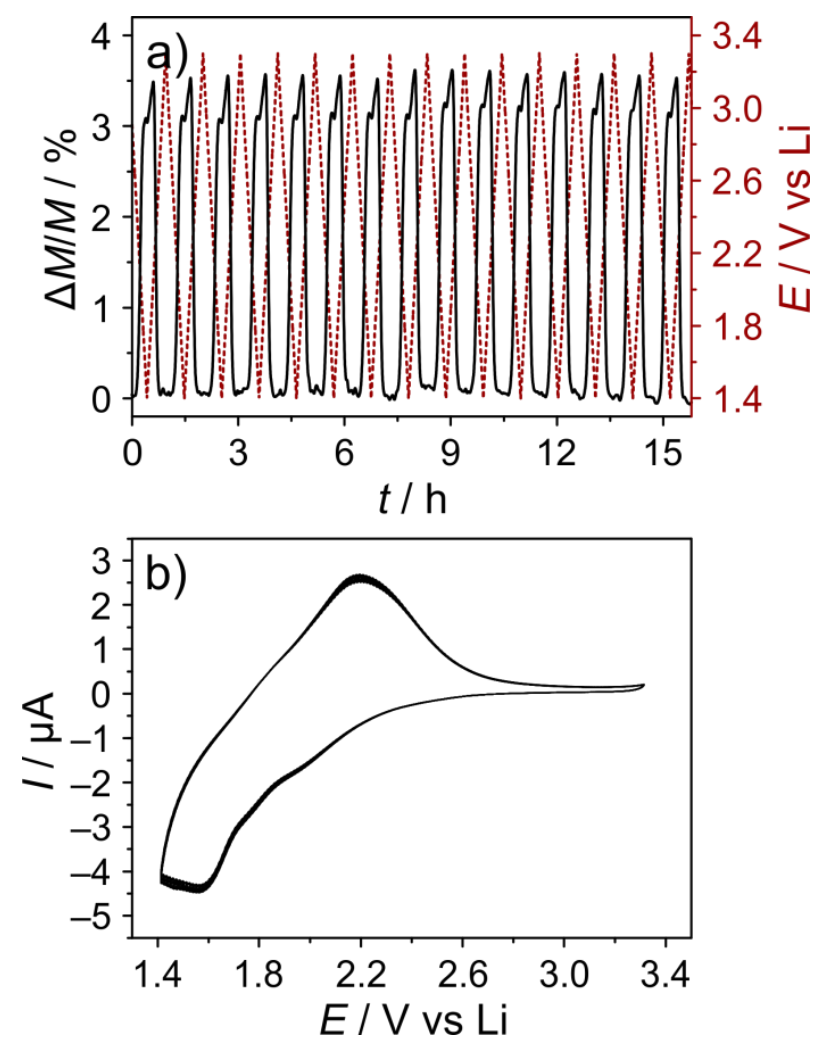

Figure 6. In situ tuning of magnetism in polymer-templated mesostructured $\mathrm{NiFe}_{2} \mathrm{O}_{4}$ thin films in the potential range between $1.4 \mathrm{~V}$ and $3.3 \mathrm{~V}$. (a) Relative change in magnetic moment (solid black line) and potential (dashed red line) versus the time and (b) the corresponding cyclic voltammetric curves at $1 \mathrm{mV} / \mathrm{s}$.

To gain more insight into the overall process, both the nano- and microstructure of the sol-gel derived materials after electrochemical cycling were studied using electron microscopy. Figure 7 shows top view SEM and HAADF STEM images comparing pristine $\mathrm{CoFe}_{2} \mathrm{O}_{4}$ and $\mathrm{NiFe}_{2} \mathrm{O}_{4}$ with cycled thin film electrodes as well as selected-area electron diffraction (SAED) patterns of $\mathrm{NiFe}_{2} \mathrm{O}_{4}$ taken before and after the tuning experiment. The imaging results establish that insertion/extraction of 
lithium into/from the spinel lattice hardly affects the nanoscale structure and compositional homogeneity, and SAED demonstrates that the microstructure is fully preserved during cycling. The 1D plots from radial integration are virtually identical, indicating that irreversible (crystalline) phase transitions can be ruled out. Besides, no significant amorphous-like structural disorder was observed by HRTEM (Figure S8, Supporting Information), thus pointing towards a topotactic reaction with lithium. ${ }^{29,32}$
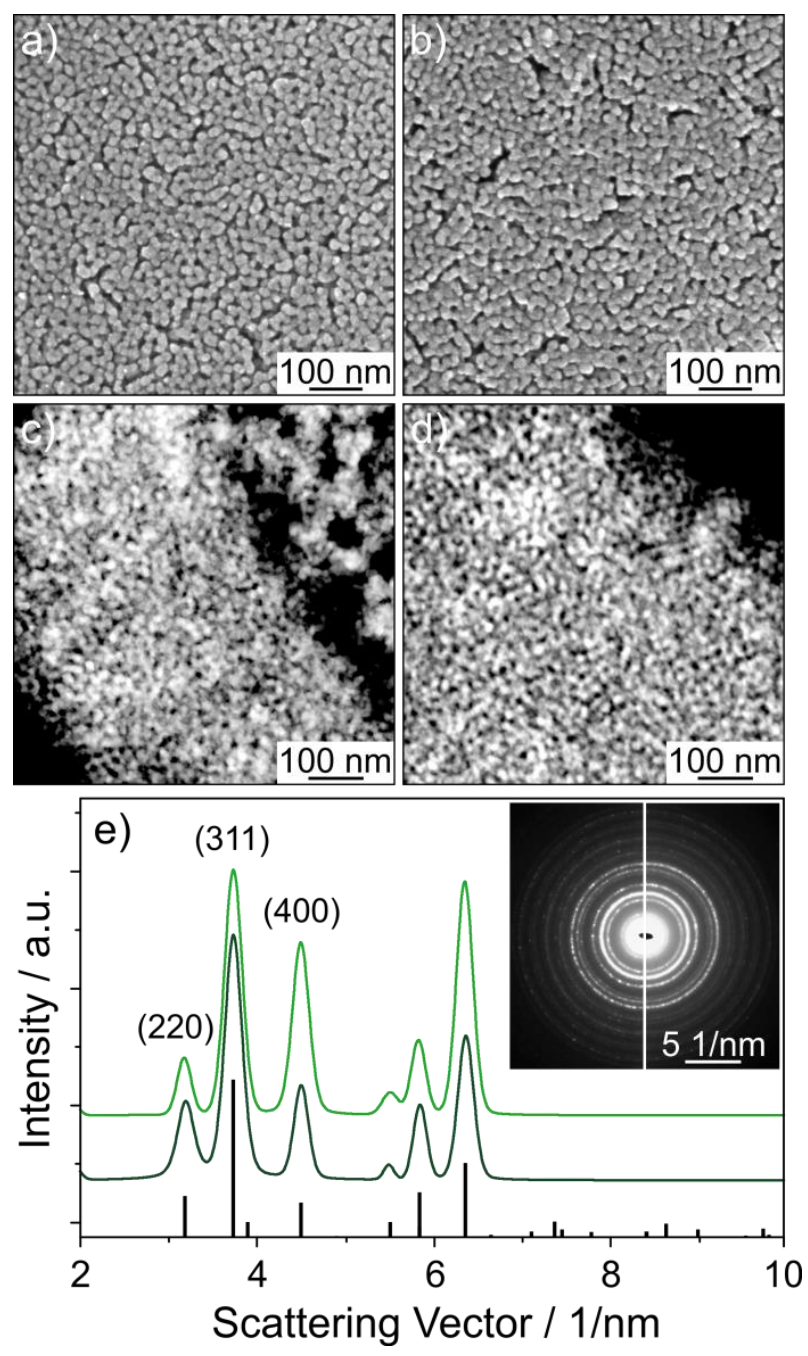

Figure 7. Electron microscopy of polymer-templated mesostructured $(a, b) \mathrm{CoFe}_{2} \mathrm{O}_{4}$ and (c-e) $\mathrm{NiFe}_{2} \mathrm{O}_{4}$ thin films ( $\mathrm{a}, \mathrm{c}$, dark green line in e) before and (b, d, light green line in e) after electrochemical cycling. (a, b) Top view SEM and (c, d) HAADF STEM images. (e) SAED patterns and the corresponding 1D plots from radial integration of diffraction intensities. The stick pattern represents ICSD reference code 28108 for cubic $\mathrm{NiFe}_{2} \mathrm{O}_{4}$.

The results of the current study confirm that robust tuning of magnetization in polymer-templated mesostructured spinel ferrite insertion electrodes is possible. Although the magnitude of the effect is relatively small, it can probably be enhanced by optimizing the cycling conditions and testing for different electrolytes. Overall, it 
seems that the tuning is strongly dependent upon the material used, and it might well be that very nanocrystalline materials are intrinsically less stable (e.g., earlier irreversible transformation from spinel to rock-salt). Besides, in most other works, the experiments were conducted ex situ, and $\mathrm{LiPF}_{6}$ in organic carbonate solvents served as electrolyte. Here, the choice of electrolyte was limited due to the reduced pressure conditions in the SQUID magnetometer. Thus, we cannot rule out that the ionic liquid-based electrolyte used for the in situ tuning experiments also plays a significant role.

\section{Conclusion}

The electrochemical tuning of magnetism in ordered mesoporous transition metal ferrites was analyzed using combined cyclic voltammetry and magnetometry measurements. To this end, cobalt, nickel, and mixed cobalt-nickel ferrites were prepared as thin films by dip-coating using an evaporation-induced self-assembly process and investigated by different microscopic, scattering, and spectroscopic techniques. The structural and compositional characterization revealed that the films can be crystallized at elevated temperatures to form single phase spinels with a similar inversion parameter $(\lambda \approx 0.7)$ while retaining both nanoscale periodicity and porosity. The magnetization results indicated significantly harder magnetic properties for the cobalt ferrites. However, all samples are magnetic at room temperature, but even more importantly, because of their ability to electrochemically react with lithium they are good model electrode materials for studying in situ changes in magnetism during cycling operation. When the cutoff potentials are controlled carefully, half-cells with an ionic liquid-based electrolyte can be cycled stably, and this in turn allows for the possibility of tuning the bulk magnetization at room temperature. Collectively, this technique - which is not based upon (traditional) charge carrier doping or strain mediation but rather makes use of facile battery redox chemistry - clearly still has lots of room for improvement and holds potential for application in the fields of micromagnetic actuation and spintronics to name a few.

\section{Associated Content}

\section{Supporting Information}

The Supporting Information is available free of charge on the ACS Publications website. CAD-drawing and photos of the tuning cell and its mounting in the SQUID magnetometer; low-magnification SEM images of thin films on ITO/Si(001) substrate; GIWAXD patterns of $\mathrm{Co}_{0.5} \mathrm{Ni}_{0.5} \mathrm{Fe}_{2} \mathrm{O}_{4}$ and $\mathrm{NiFe}_{2} \mathrm{O}_{4}$; ZFC-FC curves; tuning results for $\mathrm{Co}_{0.5} \mathrm{Ni}_{0.5} \mathrm{Fe}_{2} \mathrm{O}_{4}$; cyclic voltammograms for $\mathrm{Co}_{0.5} \mathrm{Ni}_{0.5} \mathrm{Fe}_{2} \mathrm{O}_{4}$ and $\mathrm{CoFe}_{2} \mathrm{O}_{4} ; \mathrm{HRTEM}$ images of $\mathrm{NiFe}_{2} \mathrm{O}_{4}$ before and after cycling; summary of Mössbauer fitting results; and schematics of the lithium insertion process, spin states and exchange interactions in spinel ferrites. 


\section{Author Information}

\section{Corresponding Authors}

`E-mail: lidija.dubraja@partner.kit.edu; Phone: +49 72160826364

*E-mail: torsten.brezesinski@kit.edu; Phone: +49 72160828827

\section{Notes}

The authors declare no competing financial interest.

\section{Acknowledgement}

Parts of this research were carried out at the light source PETRA III at DESY, a member of the Helmholtz Association (HGF). We thank Dr. Florian Bertram for assistance in using beamline P08. L.V. is grateful to Karlsruhe Nano Micro Facility (KNMF) and Dr. Christian Kübel for providing access to TEM at KIT. Financial support by German Research Foundation (to T.B., grant no. BR 3499/5-1; and to H.H., grant no. DA 1781/1-1) and German Academic Exchange Service (to L.A.D.) is gratefully acknowledged.

\section{References}

(1) Frey, N. A.; Peng, S.; Cheng K.; Sun, S. Magnetic Nanoparticles: Synthesis, Functionalization, and Applications in Bioimaging and Magnetic Energy Storage. Chem. Soc. Rev. 2009, 38, 2532-2542.

(2) Hu, W.; Qin, N.; Wu, G.; Lin, Y.; Li, S.; Bao, D. Opportunity of Spinel Ferrite Materials in Nonvolatile Memory Device Applications Based on Their Resistive Switching Performances. J. Am. Chem. Soc. 2012, 134, 14658-14661.

(3) Dai, Q.; Patel, K.; Donatelli, G.; Ren, S. Magnetic Cobalt Ferrite Nanocrystals for an Energy Storage Concentration Cell. Angew. Chem. Int. Ed. 2016, 55, 10439-10443.

(4) Han, S. B.; Kang, T. B.; Joo, O. S.; Jung, K. D. Water Splitting for Hydrogen Production with Ferrites. Sol. Energy 2007, 81, 623-628.

(5) Polshettiwar, V.; Luque, R.; Fihri, A.; Zhu, H.; Bouhrara, M.; Basset, J.-M. Magnetically Recoverable Nanocatalysts. Chem. Rev. 2011, 111, 3036-3075.

(6) Duanmu, C.; Saha, I.; Zheng, Y.; Goodson, B. M.; Gao, Y. DendronFunctionalized Superparamagnetic Nanoparticles with Switchable Solubility in Organic and Aqueous Media: Matrices for Homogeneous Catalysis and Potential MRI Contrast Agents. Chem. Mater. 2006, 18, 5973-5981.

(7) Fan, H.-M.; Yi, J.-B.; Yang, Y.; Kho, K.-W.; Tan, H.-R.; Shen, Z.-X.; Ding, J., Sun, X.-W.; Olivo, M. C.; Feng, Y.-P. Single-Crystalline $\mathrm{MFe}_{2} \mathrm{O}_{4}$ Nanotubes/Nanorings Synthesized by Thermal Transformation Process for Biological Applications. ACS Nano 2009, 3, 2798-2808. 
(8) Zhang, H.; Li, L.; Liu, X. L.; Jiao, J.; Ng, C.-T.; Yi, J. B.; Luo, Y. E.; Bay, B.-H.; Zhao, L. Y.; Peng, M. L.; Gu, N.; Fan, H. M. Ultrasmall Ferrite Nanoparticles Synthesized via Dynamic Simultaneous Thermal Decomposition for HighPerformance and Multifunctional $T_{1}$ Magnetic Resonance Imaging Contrast Agent. ACS Nano 2017, 11, 3614-3631.

(9) Lu, A.-H.; Salabas, E. L.; Schüth, F. Magnetic Nanoparticles: Synthesis, Protection, Functionalization, and Application. Angew. Chem. Int. Ed. 2007, 46, 1222-1244.

(10) Thanh, N. T. K.; Green, L. A. W. Functionalisation of Nanoparticles for Biomedical Applications. Nano Today 2010, 5, 213-230.

(11) Dai, Q.; Berman, D.; Virwani, K.; Frommer, J.; Jubert, P.-O.; Lam, M.; Topuria, T.; Imaino, W.; Nelson A. Self-Assembled Ferrimagnet-Polymer Composites for Magnetic Recording Media. Nano Lett. 2010, 10, 3216-3221.

(12) Quickel, T. E.; Le, V. H.; Brezesinski T.; Tolbert, S. H. On the Correlation between Nanoscale Structure and Magnetic Properties in Ordered Mesoporous Cobalt Ferrite $\left(\mathrm{CoFe}_{2} \mathrm{O}_{4}\right)$ Thin Films. Nano Lett. 2010, 10, 2982-2988.

(13) Pettigrew, K. A.; Long, J. W.; Carpenter, E. E.; Baker, C. C.; Lytle, J. C.; Chervin, C. N.; Logan, M. S.; Stroud, R. M.; Rolison, D. R. Nickel Ferrite Aerogels with Monodisperse Nanoscale Building Blocks-The Importance of Processing Temperature and Atmosphere. ACS Nano 2008, 2, 784-790.

(14) Zhang, J.; Fu, J.; Tan, G.; Li, F.; Luo, C.; Zhao, J.; Xie, E.; Xue, D.; Zhang, H.; Mellors, N. J.; Peng, Y. Nanoscale Characterization and Magnetic Reversal Mechanism Investigation of Electrospun $\mathrm{NiFe}_{2} \mathrm{O}_{4}$ Multi-Particle-Chain Nanofibers. Nanoscale 2012, 4, 2754-2759.

(15) Jacob, J.; Khadar, M. A. Investigation of Mixed Spinel Structure of Nanostructured Nickel Ferrite. J. Appl. Phys. 2010, 107, 114310.

(16) Reitz, C.; Suchomski, C.; Haetge, J.; Leichtweiss, T.; Jagličić, Z.; Djerdj, I.; Brezesinski, T. Soft-Templating Synthesis of Mesoporous Magnetic CuFe ${ }_{2} \mathrm{O}_{4}$ Thin Films with Ordered 3D Honeycomb Structure and Partially Inverted Nanocrystalline Spinel Domains. Chem. Commun. 2012, 48, 4471-4473.

(17) Reitz, C.; Suchomski, C.; Chakravadhanula, V. S. K.; Djerdj, I.; Jagličić, Z.; Brezesinski, T. Morphology, Microstructure, and Magnetic Properties of Ordered Large-Pore Mesoporous Cadmium Ferrite Thin Film Spin Glasses. Inorg. Chem. 2013, 52, 3744-3754.

(18) Vasundhara, K.; Achary, S. N.; Deshpande, S. K.; Babu, P. D.; Meena, S. S.; Tyagi, A. K. Size Dependent Magnetic and Dielectric Properties of Nano $\mathrm{CoFe}_{2} \mathrm{O}_{4}$ Prepared by a Salt Assisted Gel-Combustion Method. J. Appl. Phys. 2013, 113, 194101.

(19) Chinnasamy, C. N.; Narayanasamy, A.; Ponpandian, N.; Chattopadhyay, K.; Guérault, H.; Greneche, J.-M. Magnetic Properties of Nanostructured Ferrimagnetic Zinc Ferrite. J. Phys.: Condens. Matter 2000, 12, 7795-7805.

(20) Chu, Y.-Q.; Fu, Z.-W.; Qin, Q.-Z. Cobalt Ferrite Thin Films as Anode Material for Lithium Ion Batteries. Electrochim. Acta 2004, 49, 4915-4921. 
(21) Lavela, P.; Tirado, J. L. $\mathrm{CoFe}_{2} \mathrm{O}_{4}$ and $\mathrm{NiFe}_{2} \mathrm{O}_{4}$ Synthesized by Sol-Gel Procedures for Their Use as Anode Materials for Li Ion Batteries. J. Power Sources 2007, 172, 379-387.

(22) Cabana, J.; Monconduit, L.; Larcher, D.; Palacín, M. R. Beyond IntercalationBased Li-Ion Batteries: The State of the Art and Challenges of Electrode Materials Reacting Through Conversion Reactions. Adv. Mater. 2010, 22, E170-E192.

(23) Bresser, D.; Paillard, E.; Kloepsch, R.; Krueger, S.; Fiedler, M.; Schmitz, R.; Baither, D.; Winter, M.; Passerini, S. Carbon Coated $\mathrm{ZnFe}_{2} \mathrm{O}_{4}$ Nanoparticles for Advanced Lithium-Ion Anodes. Adv. Energy Mater. 2013, 3, 513-523.

(24) Won, J. M.; Choi, S. H.; Hong, Y. J.; Ko, Y. N.; Kang, Y. C. Electrochemical Properties of Yolk-Shell Structured $\mathrm{ZnFe}_{2} \mathrm{O}_{4}$ Powders Prepared by a Simple Spray Drying Process as Anode Material for Lithium-Ion Battery. Sci. Rep. 2014, 4, 5857.

(25) Suchomski, C.; Breitung, B.; Witte, R.; Knapp, M.; Bauer, S.; Baumbach, T.; Reitz, C.; Brezesinski, T. Microwave Synthesis of High-Quality and Uniform 4 $\mathrm{nm} \mathrm{ZnFe}_{2} \mathrm{O}_{4}$ Nanocrystals for Application in Energy Storage and Nanomagnetics. Beilstein J. Nanotechnol. 2016, 7, 1350-1360.

(26) Zeng, G.; Shi, N.; Hess, M.; Chen, X.; Cheng, W.; Fan, T.; Niederberger, M. A General Method of Fabricating Flexible Spinel-Type Oxide/Reduced Graphene Oxide Nanocomposite Aerogels as Advanced Anodes for Lithium-Ion Batteries. ACS Nano 2015, 9, 4227-4235.

(27) Zhang, Z.; Li, W.; Zou, R.; Kang, W.; Chui, Y. S.; Yuen, M. F.; Lee, C.-S.; Zhang, W. Layer-Stacked Cobalt Ferrite $\left(\mathrm{CoFe}_{2} \mathrm{O}_{4}\right)$ Mesoporous Platelets for High-Performance Lithium Ion Battery Anodes. J. Mater. Chem. A 2015, 3, 6990-6997.

(28) Xiong, Q. Q.; Tu, J. P.; Shi, S. J.; Liu, X. Y.; Wang, X. L.; Gu, C. D. Ascorbic Acid-Assisted Synthesis of Cobalt Ferrite $\left(\mathrm{CoFe}_{2} \mathrm{O}_{4}\right)$ Hierarchical Flower-Like Microspheres with Enhanced Lithium Storage Properties. J. Power Sources 2014, 256, 153-159.

(29) Dasgupta, S.; Das, B.; Knapp, M.; Brand, R. A.; Ehrenberg, H.; Kruk, R.; Hahn, $\mathrm{H}$. Intercalation-Driven Reversible Control of Magnetism in Bulk Ferromagnets. Adv. Mater. 2014, 26, 4639-4644.

(30) Tsuchiya, T.; Terabe, K.; Ochi, M.; Higuchi, T.; Osada, M.; Yamashita, Y.; Ueda, S.; Aono, M. In Situ Tuning of Magnetization and Magnetoresistance in $\mathrm{Fe}_{3} \mathrm{O}_{4}$ Thin Film Achieved with All-Solid-State Redox Device. ACS Nano 2016, 10, 1655-1661.

(31) Dasgupta, S.; Das, B.; Li, Q.; Wang, D.; Baby, T. T.; Indris, S.; Knapp, M.; Ehrenberg, H.; Fink, K.; Kruk, R.; Hahn, H. Toward On-and-Off Magnetism: Reversible Electrochemistry to Control Magnetic Phase Transitions in Spinel Ferrites. Adv. Funct. Mater. 2016, 26, 7507-7515.

(32) Reitz, C.; Suchomski, C.; Wang, D.; Hahn, H.; Brezesinski, T. In Situ Tuning of Magnetization via Topotactic Lithium Insertion in Ordered Mesoporous Lithium Ferrite Thin Films. J. Mater. Chem. C 2016, 4, 8889-8896. 
(33) Zhang, Q.; Luo, X.; Wang, L.; Zhang, L.; Khalid, B.; Gong, J.; Wu, H. LithiumIon Battery Cycling for Magnetism Control. Nano Lett. 2016, 16, 583-587.

(34) Wei, G.; Wei, L.; Wang, D.; Tian, Y.; Chen, Y.; Yan, S.; Mei, L.; Jiao, J. Reversible Control of the Magnetization of $\mathrm{Fe}_{3} \mathrm{O}_{4}$ via Lithium lons. RSC Adv. 2017, 7, 2644-2649.

(35) Wei, G.; Wei, L.; Wang, D.; Chen, Y.; Tian, Y.; Yan, S.; Mei, L.; Jiao, J. Reversible Control of the Magnetization of Spinel Ferrites Based Electrodes by Lithium-Ion Migration. Sci. Rep. 2017, 7, 12554.

(36) Brinker, C. J.; Lu, Y.; Sellinger, A.; Fan, H. Evaporation-Induced Self-Assembly: Nanostructures Made Easy. Adv. Mater. 1999, 11, 579-585.

(37) Lu, Y.; Ganguli, R.; Drewien, C. A.; Anderson, M. T.; Brinker, C. J.; Gong, W.; Guo, Y.; Soyez, H.; Dunn, B.; Huang, M. H.; Zink, J. I. Continuous Formation of Supported Cubic and Hexagonal Mesoporous Films by Sol-Gel Dip-Coating. Nature 1997, 389, 364-368.

(38) Grosso, D.; Cagnol, F.; Soler-Illia, G. J. de A. A.; Crepaldi, E. L.; Amenitsch, H.; Brunet-Bruneau, A.; Bourgeois, A.; Sanchez, C. Fundamentals of Mesostructuring Through Evaporation-Induced Self-Assembly. Adv. Funct. Mater. 2004, 14, 309-322.

(39) Lee, C. S.; Lee, H.; Westervelt, R. M. Microelectromagnets for the Control of Magnetic Nanoparticles. Appl. Phys. Lett. 2001, 79, 3308-3310.

(40) Ramadan, W.; Yu, C.; Samper, V.; Poenar, D. P. Microcoils for Transport of Magnetic Beads. Appl. Phys. Lett. 2006, 88, 032501-1-032501-3.

(41) Siegel, A. C.; Shevkoplyas, S. S.; Weibel, D. B.; Bruzewicz, D. A.; Martinez, A. W.; Whitesides, G. M. Cofabrication of Electromagnets and Microfluidic Systems in Poly(dimethylsiloxane). Angew. Chem. Int. Ed. 2006, 45, 68776882.

(42) Quinn, E. J.; Hernandez-Santana, A.; Hutson, D. M.; Pegrum, C. M.; Graham, D.; Smith, W. E. A SERRS-Active Bead/Microelectromagnet System for SmallScale Sensitive Molecular Identification and Quantitation. Small 2007, 3, 13941397.

(43) Choi, S. Y.; Lee, B.; Carew, D. B.; Mamak, M.; Peiris, F. C.; Speakman, S.; Chopra, N.; Ozin, G. A. 3D Hexagonal $(R-3 m)$ Mesostructured Nanocrystalline Titania Thin Films: Synthesis and Characterization. Adv. Funct. Mater. 2006, 16, 1731-1738.

(44) Sanchez, C.; Boissière, C.; Grosso, D.; Laberty, C.; Nicole, L. Design, Synthesis, and Properties of Inorganic and Hybrid Thin Films Having Periodically Organized Nanoporosity. Chem. Mater. 2008, 20, 682-737.

(45) Ortel, E.; Fischer, A.; Chuenchom, L.; Polte, J.; Emmerling, F.; Smarsly, B. M.; Kraehnert, R. New Triblock Copolymer Templates, PEO-PB-PEO, for the Synthesis of Titania Films with Controlled Mesopore Size, Wall Thickness, and Bimodal Porosity. Small 2012, 8, 298-309.

(46) Sawatzky, G. A.; van der Woude, F.; Morrish, A. H. Cation Distributions in Octahedral and Tetrahedral Sites of the Ferrimagnetic Spinel $\mathrm{CoFe}_{2} \mathrm{O}_{4}$. J. Appl. Phys. 1968, 39, 1204-1206. 
(47) Peddis, D.; Yaacoub, N.; Ferretti, M.; Martinelli, A.; Piccaluga, G.; Musinu, A.; Cannas, C.; Navarra, G.; Greneche, J. M.; Fiorani, D. Cationic Distribution and Spin Canting in $\mathrm{CoFe}_{2} \mathrm{O}_{4}$ Nanoparticles. J. Phys.: Condens. Matter 2011, 23, 426004.

(48) Chen, C. J.; Greenblatt, M.; Waszczak, J. V. Lithium Insertion Compounds of $\mathrm{LiFe}_{5} \mathrm{O}_{8}, \mathrm{Li}_{2} \mathrm{FeMn}_{3} \mathrm{O}_{8}$, and $\mathrm{Li}_{2} \mathrm{ZnMn}_{3} \mathrm{O}_{8}$. J. Solid State Chem. 1986, 64, 240248.

(49) Domingues, P. H.; Neto, J. M.; Silva, M. R.; El Massalami, M. The Observation of Phase Transition in $\mathrm{LiFe}_{3} \mathrm{O}_{4}$ by Mössbauer Spectroscopy. Hyperfine Interact. 2001, 133, 41-46.

\section{TOC Graphic}

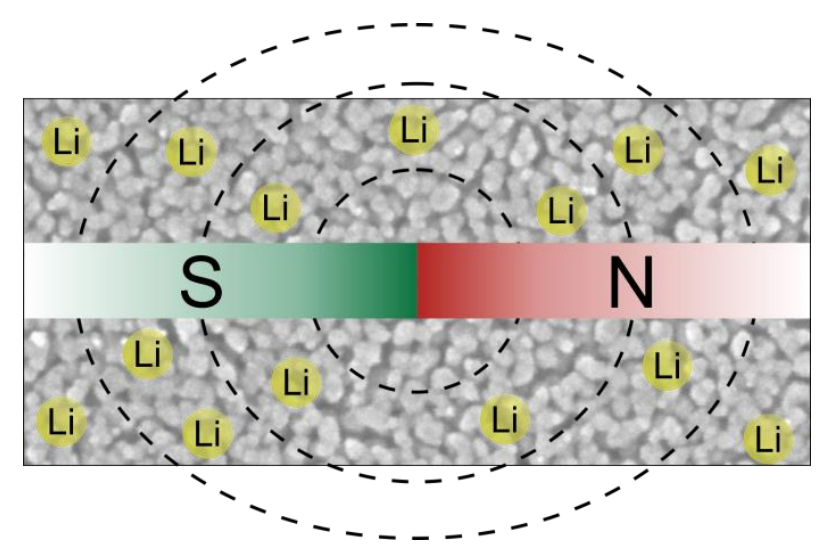

